\title{
Genomic instability of human embryonic stem cell lines using different passaging culture methods
}

\author{
Lucie Tosca $^{1,2,3^{*}}$, Olivier Feraud ${ }^{3}$, Aurélie Magniez ${ }^{3}$, Cécile Bas ${ }^{1,3}$, Frank Griscelli, ${ }^{3,4}$, Annelise Bennaceur-Griscelli, ${ }^{2,3,5}$ \\ and Gérard Tachdjian ${ }^{1,2,3}$
}

\begin{abstract}
Background: Human embryonic stem cells exhibit genomic instability that can be related to culture duration or to the passaging methods used for cell dissociation. In order to study the impact of cell dissociation techniques on human embryonic stem cells genomic instability, we cultured $\mathrm{H} 1$ and $\mathrm{H} 9$ human embryonic stem cells lines using mechanical/manual or enzymatic/collagenase-IV dissociation methods. Genomic instability was evaluated at early $(<\mathrm{p} 60)$ and late $(>\mathrm{p} 60)$ passages by using oligonucleotide based array-comparative genomic hybridization $105 \mathrm{~K}$ with a mean resolution of $50 \mathrm{~Kb}$.
\end{abstract}

Results: DNA variations were mainly located on subtelomeric and pericentromeric regions with sizes $<100 \mathrm{~Kb}$. In this study, 9 recurrent genomic variations were acquired during culture including the well known duplication 20q11.21. When comparing cell dissociation methods, we found no significant differences between DNA variations number and size, DNA gain or DNA loss frequencies, homozygous loss frequencies and no significant difference on the content of genes involved in development, cell cycle tumorigenesis and syndrome disease. In addition, we have never found any malignant tissue in 4 different teratoma representative of the two independent stem cell lines.

Conclusions: These results show that the occurrence of genomic instability in human embryonic stem cells is similar using mechanical or collagenase IV-based enzymatic cell culture dissociation methods. All the observed genomic variations have no impact on the development of malignancy.

Keywords: Cell passaging methods, Collagenase IV, Human embryonic stem cells, Array-CGH, Genomic instability

\section{Background}

Human embryonic stem cells (hESC) are derived from inner cell mass of blastocyst stage embryos [1]. These cells exhibit pluripotency and self-renewal properties. Indeed, hESC can differentiate into the three germlines that constitute a potential use of the cells in therapeutics, transplantation, drug testing as well as to study early embryogenesis. Even though it is possible to cultivate for a long time hESC and maintain their undifferentiated state the current in vitro culture conditions are not optimal and still new methods need to be developed. Previous studies showed that hESC could acquire nonrandom genetic changes after prolonged cell passages affecting cell growth and differentiation potential $[2,3]$.

\footnotetext{
*Correspondence: lucie.tosca@abc.aphp.fr

'AP-HP, Histologie-Embryologie-Cytogénétique, Hôpitaux Universitaires Paris Sud, Clamart F-92141, France

${ }^{2}$ Université Paris Sud, Le Kremlin-Bicêtre F-94275, France

Full list of author information is available at the end of the article
}

These genomic variations represent a selection providing to the cells a strong advantage $[4,5]$. The accumulation of chromosomal abnormalities during hESC culture may be due to decrease efficiency of base excision repair, surnumerary centrosomes and/or malfunction of the cell cycle checkpoints [5-8]. Environmental factors may influence genomic behavior such as culture media, feeder layer or dissociation methods used for cell passaging. Impact of cell culture dissociation techniques on genomic instability in particular enzymatic based-methods was underlined by many authors [2,9-15]. Others studies observed chromosomal integrity when mechanical/manual dissociation was used [16-18]. However, these studies were based on conventional cytogenetic techniques allowing a chromosomal study with a resolution of $10 \mathrm{Mb}$. Some authors combined these assays with chromosome based-comparative genomic hybridization (classic CGH) allowing an overview of the whole genome for the detection of DNA copy changes. But, similarly to the karyotype, 
resolution of classic CGH may not allow detection of genomic variations smaller than $10 \mathrm{Mb}$.

Recently, studies on hESC genomic instability were obtained using microarray-based comparative genomic hybridization (array-CGH) or single nucleotide polymorphisms (SNP) array allowing a high resolution chromosomal study under $100 \mathrm{~Kb}$ [19-22]. Nevertheless, the effects of passaging culture methods on genomic instability were not investigated using array-CGH.

In this study, we carried out an extensive molecular cytogenetic analysis on two hESC lines $\mathrm{H} 1$ and $\mathrm{H} 9$ cultured beyond 60 passages on mouse embryonic fibroblasts (MEF) and passaged by mechanical or collagenase IV-based enzymatic methods. We used array-CGH with a mean resolution of $50 \mathrm{~Kb}$ to uncover subkaryotypic genome alterations and subsequent gene content. Teratoma formation potency was realized in order to assess the functional impact of the dissociation methods used.

\section{Results}

Analysis of pluripotent markers expression across the time During the successive cell passages, the hESC lines showed no morphological evolution that may indicate that they had lost their pluripotent status. However, to ensure their pluripotent state, we performed an expression analysis of three specific markers of pluripotence (HESCA, SSEA-4 and TRA $1-60)$ at early $(<\mathrm{p} 60)$ and late $(>\mathrm{p} 60)$ passages (Additional file 1: Figure S1). In all cases, we observed an extreme stability of expression of these three markers between early and late passages (Additional file 1: Figure S1). These results confirmed the maintenance of the pluripotent state of these cells during this study.

\section{Analysis of $\mathrm{H} 1$ and $\mathrm{H} 9 \mathrm{hESC}$ lines by conventional cytogenetic and FISH analysis}

A systematic chromosomal assay using karyotype and FISH was realized at regular passages for the two cell lines $\mathrm{H} 1$ and $\mathrm{H} 9$ using both passaging methods (Additional file 2: Table S5). Analysis for $\mathrm{H} 1$ cell lines showed a normal male karyotype 46,XY (Additional file 3: Figure S2A). Similarly, H9 cell lines showed normal female karyotype 46,XX (Additional file 3: Figure S2B).

The centromeric probes specific for chromosomes 12 and 17 showed normal hybridization excluding chromosomes 12 and 17 aneuploidies. BACs RP5-1018D12 and RP3$324 \mathrm{O} 17$ hybridization gave one signal on both chromosomes 20 thus excluding the recurrent 20q11.2 duplication.

\section{Global characterization of genomic instability by array-CGH in $\mathrm{H} 1$ and $\mathrm{H} 9 \mathrm{hESC}$ lines}

First we analyzed array-CGH results considering all genomic variations i.e. including polymorphic DNA variations described in Toronto Database of Genomic Variants (http://projects.tcag.ca/cgi-bin/variation/gbrowse/hg18/). Individual representation of genomic variations of the two hESC lines is shown in Figure 1. We observed that the genomic variations were mainly located on subtelomeric and pericentromeric regions.

Table 1 mentions 9 recurrent DNA variations occurring during culture of the hESC lines. These genomic variations are described according to chromosomal position, size, gene content and type (gain/loss). We observed that more than half-variations (6/9) carried relevant genes involved in development, cell cycle, growth, apoptosis, tumorigenesis and/or syndrome/ disease (Table 1). An example of plots of the 1q21.3 region is presented in Additional file 4: Figure S3.

Detailed characteristics of total genomic variations comparing early $(<\mathrm{p} 60)$ manual, early enzymatic $(<\mathrm{p} 60)$ and late enzymatic $(>\mathrm{p} 60)$ passages are shown in Figure 2. Results are presented as mean of the two cell lines (early manual passages, H1p56, H9p30; early enzymatic passages, H1p56, H9p30; late enzymatic passages, H1p159, H9p87). Total number of genomic variations was stable after enzymatic technique $(13.50 \pm 3.88)$ compared to manual technique $(12.00 \pm 2.12)$ at early passages; and increased by about 3-fold after late enzymatic passages $(42.00 \pm 23.33)$ compared to early enzymatic passages $(13.50 \pm 3.88)$ but were not significantly different (Figure 2A). There were no significant differences between the percentages of DNA losses or DNA gains between early manual and early enzymatic passages (loss, $60.00 \pm 18.85 \%$ versus $45.39 \pm$ $20.93 \%$; gain, $40.00 \pm 18.85 \%$ versus $54.60 \pm 20.93 \%$ ) and between early and late enzymatic passages (loss, $45.39 \pm$ $20.93 \%$ versus $77.33 \pm 7.54 \%$; gain, $54.60 \pm 20.93 \%$ versus $22.66 \pm 7.54 \%$ ) (Figure 2B). The percentages of homozygous copy loss were not significantly different between both cell dissociation methods at early passages (early manual, $56.41 \pm 7.25 \%$; early enzymatic, $41.66 \pm 17.67 \%$ ) and between enzymatic passages (early enzymatic, $41.66 \pm$ $17.67 \%$; late enzymatic, $32.57 \pm 0.53 \%$ ) (Figure $2 \mathrm{C}$ ).

When looking at the size of the variations, we observed no significant differences between early manual and early enzymatic passages or early enzymatic and late enzymatic passages (Figure 2D). However, for each group small genomic variations $<100 \mathrm{~Kb}$ were more importantly observed than intermediate genomic variations $(100 \mathrm{~Kb}-1 \mathrm{Mb})$ and than large genomic variations (>1 Mb) (Figure 2D). Indeed, for early manual group small genomic variations were about 3-fold higher than intermediate genomic variations $(67.77 \pm 8.64 \%$ versus $23.33 \pm 7.07 \%$ ) and by about 7.5 -fold higher than large genomic variations $(67.77 \pm 8.64 \%$ versus $8.88 \pm 5.97 \%)$ (Figure 2D). For early enzymatic group, small variations were about 6.5 -fold higher than intermediate variations $(81.25 \pm 13.25 \%$ versus $12.50 \pm 8.83 \%)$ and by about 13 fold higher than large variations $(81.25 \pm 13.25 \%$ versus 


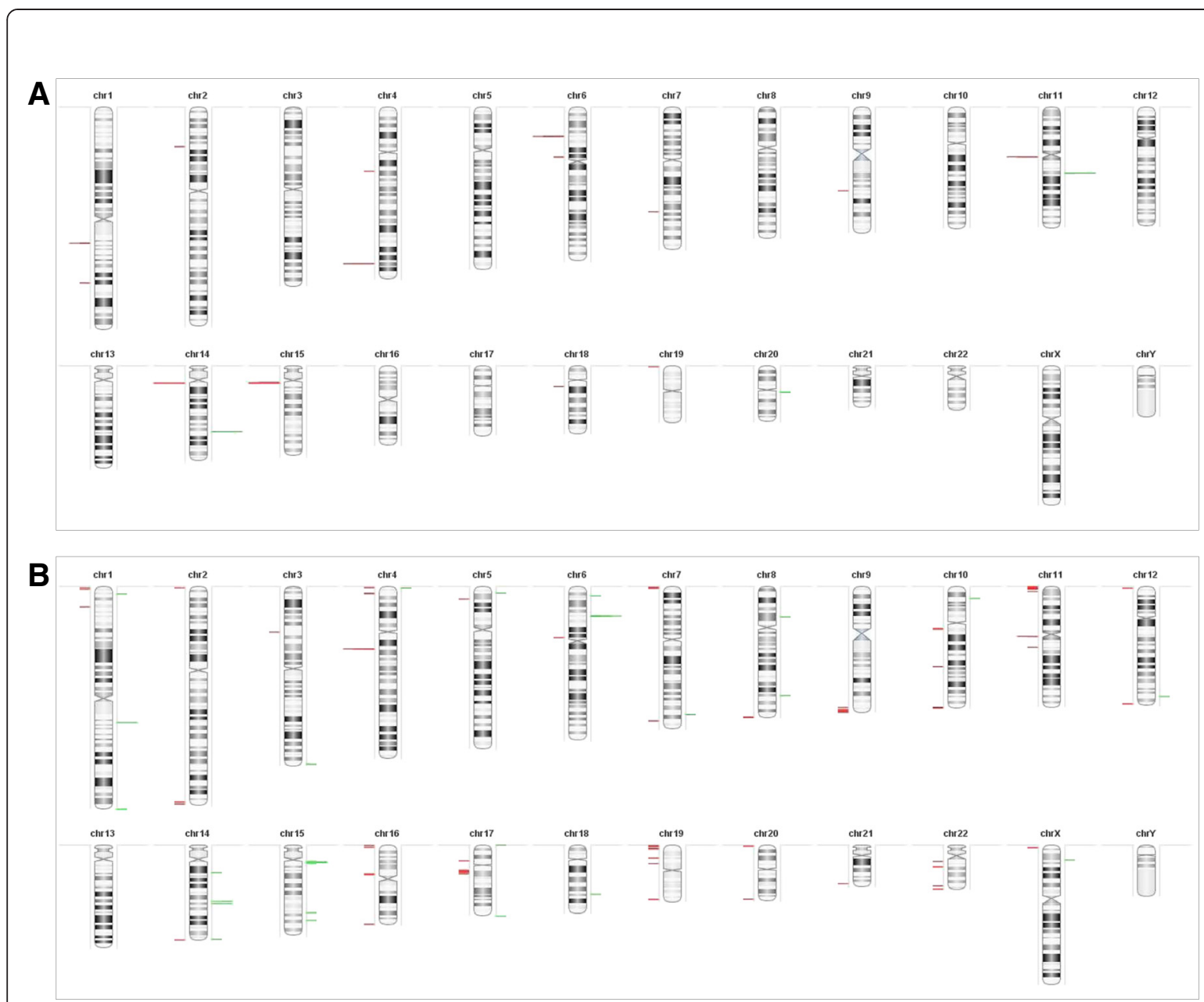

Figure 1 Array-CGH DNA variations distribution. Individual distribution of total chromosomal aberrations for H1 (A) and H9 (B) hESC cell lines including polymorphic CNVs described in Toronto Database of Genomic Variants. Each bar represented one genomic variation: green, gain; red, loss.

Table 1 Recurrent genomic variations acquired during hESC $\mathrm{H} 1$ and $\mathrm{H} 9$ culture

\begin{tabular}{|c|c|c|c|c|c|c|c|c|}
\hline $\begin{array}{l}\text { Chromosome } \\
\text { region }\end{array}$ & Size (kb min-max) & Common genes & $\begin{array}{l}\mathrm{H} 1 \mathrm{M} \\
\text { early }\end{array}$ & $\begin{array}{l}\mathrm{H} 1 \mathrm{E} \\
\text { early }\end{array}$ & $\begin{array}{l}\mathrm{H1} \mathrm{E} \\
\text { late }\end{array}$ & $\begin{array}{l}\mathrm{H} 9 \mathrm{M} \\
\text { early }\end{array}$ & $\begin{array}{l}\mathrm{H} 9 \mathrm{E} \\
\text { early }\end{array}$ & $\begin{array}{l}\mathrm{H} 9 \mathrm{E} \\
\text { late }\end{array}$ \\
\hline $1 \mathrm{q} 21.3$ & $12.42-25.84$ & LCE3C $^{4}$ & $L$ & - & L & $\mathrm{G}$ & - & $G$ \\
\hline $4 p 16.3$ & $27.74-253.75$ & FAM53A & - & - & - & - & G & L \\
\hline $6 p 21.32$ & $37.12-81.43$ & $\mathrm{HLA}^{\mathrm{DLBB}} 5^{4}$ & L & L & L & G & G & G \\
\hline $11 q 11$ & $54.62-82.97$ & OR4C11, OR4P4, OR4S2 & L & L & L & L & - & L \\
\hline $14 q 23.2$ & 295.35 & $\mathrm{KCNH} 5, \mathrm{RHO}^{3}, \mathrm{GPHB} 5$ & - & - & - & G & - & G \\
\hline $14 q 23.3$ & 398.69 & FUT8 $^{3}$ & - & - & - & G & - & G \\
\hline $15 q 11.2$ & 1270.33-1779-68 & LOC283755, A26B1, OR4M2, OR4N4, LOC650137 & L & L & L & G & - & G \\
\hline $20 q 11.21$ & 1022.42 & $\begin{array}{l}\text { DEFB1 15-116,118-119,121,123-124, REM1, HM13, } \\
{\text { ID1 }{ }^{2}, \text { COX4I24 }}^{4}, \text { BCL2L1 }{ }^{2}\end{array}$ & - & - & G & - & - & - \\
\hline $22 q 13.2$ & 17.66 & SCUBE $1^{1}$ & - & - & - & - & - & L \\
\hline
\end{tabular}

Recurrent genomic variations observed during $\mathrm{hESC}$ lines $\mathrm{H} 1$ and $\mathrm{H} 9$ in vitro culture using manual or enzymatic techniques. Chromosomal region, minimal/maximal sizes, common genes and variation type (loss/gain) are mentioned. E, enzymatic passages; $\mathrm{G}$, gain; L, loss; M, manual passages; max, maximal; min, minimal; ${ }^{1}$, genes related to development; ${ }^{2}$, genes related to cell cycle, growth and apoptosis; ${ }^{3}$, genes related to tumorigenesis; ${ }^{4}$, genes related to syndrome and disease. 


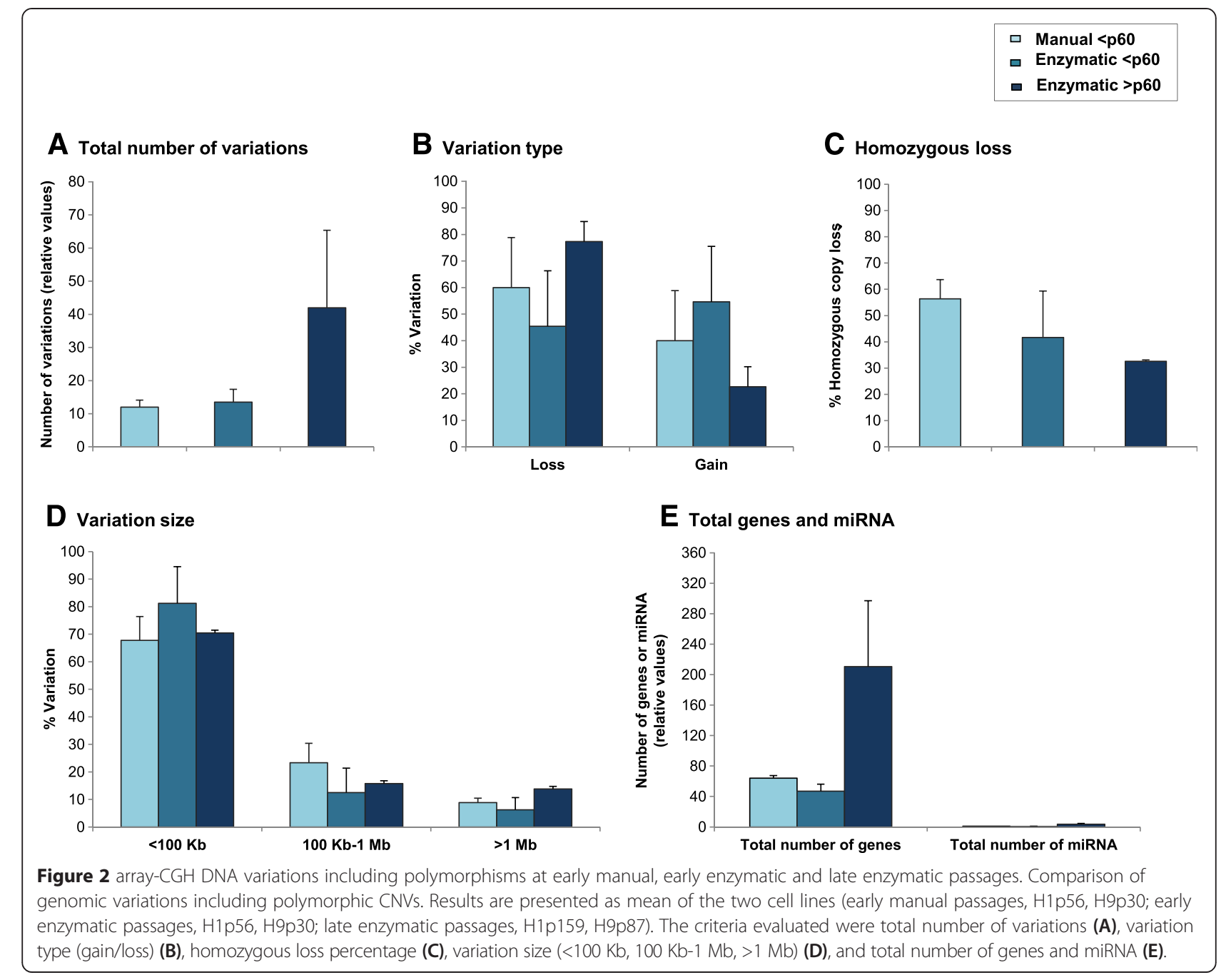

$6.25 \pm 4.41 \%$ ) (Figure 2D). For late enzymatic group, small variations were about 4.5 -fold higher than intermediate variations $(70.44 \pm 10.52 \%$ versus $15.77 \pm 1.76 \%)$ and by about 5 -fold higher than large variations (70.44 \pm $10.52 \%$ versus $13.77 \pm 5.97 \%$ ) (Figure $2 \mathrm{D}$ ).

Total number of genes included in genomic variations was not significantly different between early manual and early enzymatic passages $(64.00 \pm 3.53$ and $47.00 \pm 9.19$, respectively) and between early enzymatic and late enzymatic passages (47.00 \pm 9.19 and $210.5 \pm 86.62$, respectively) (Figure 2E). The number of miRNA included in genomic variations was quite similar between early manual $(1.00 \pm 0.00)$ and early enzymatic $(0.50 \pm 0.35)$ methods; and between early $(0.50 \pm 0.35)$ and late $(3.50$ \pm 1.06 ) enzymatic methods (Figure $2 \mathrm{E}$ ).

\section{Characterization of genomic variations without polymorphic CNVs by array-CGH of $\mathrm{H} 1$ and $\mathrm{H} 9 \mathrm{hESC}$ cell lines}

Secondly, we interpreted array-CGH results without polymorphic variants described in Toronto Database of
Genomic Variants. The content of this database is only representing structural variation identified in healthy control samples. Thus remaining DNA variation can be interpreted as potentially pathogenic or of unknown signification. Comparison between early manual $(<\mathrm{p} 60)$, early enzymatic $(<\mathrm{p} 60)$ and late enzymatic $(>\mathrm{p} 60)$ passages is shown in Figure 3. Results are presented as mean of the two cell lines (early manual passages, H1p56, H9p30; early enzymatic passages, H1p56, H9p30; late enzymatic passages, H1p159, H9p87).

Concerning the size of DNA variations, we did not observe significant differences between early manual and early enzymatic methods for small genomic variations $<100 \mathrm{~Kb}(67.85 \pm 12.62 \%$ versus $83.33 \pm 11.78 \%)$, intermediate genomic variations $100 \mathrm{~Kb}-1 \mathrm{Mb}(32.14 \pm$ $12.62 \%$ versus $16.66 \pm 11.78 \%)$ and large genomic variations $(0.00 \pm 0.00 \%$ versus $0.00 \pm 0.00 \%)$ (Figure $3 \mathrm{~A}$ ). Similarly, we did not observe significant differences between early enzymatic and late enzymatic methods for small $(83.33 \pm 11.78 \%$ versus $62.93 \pm 9.14 \%)$, 

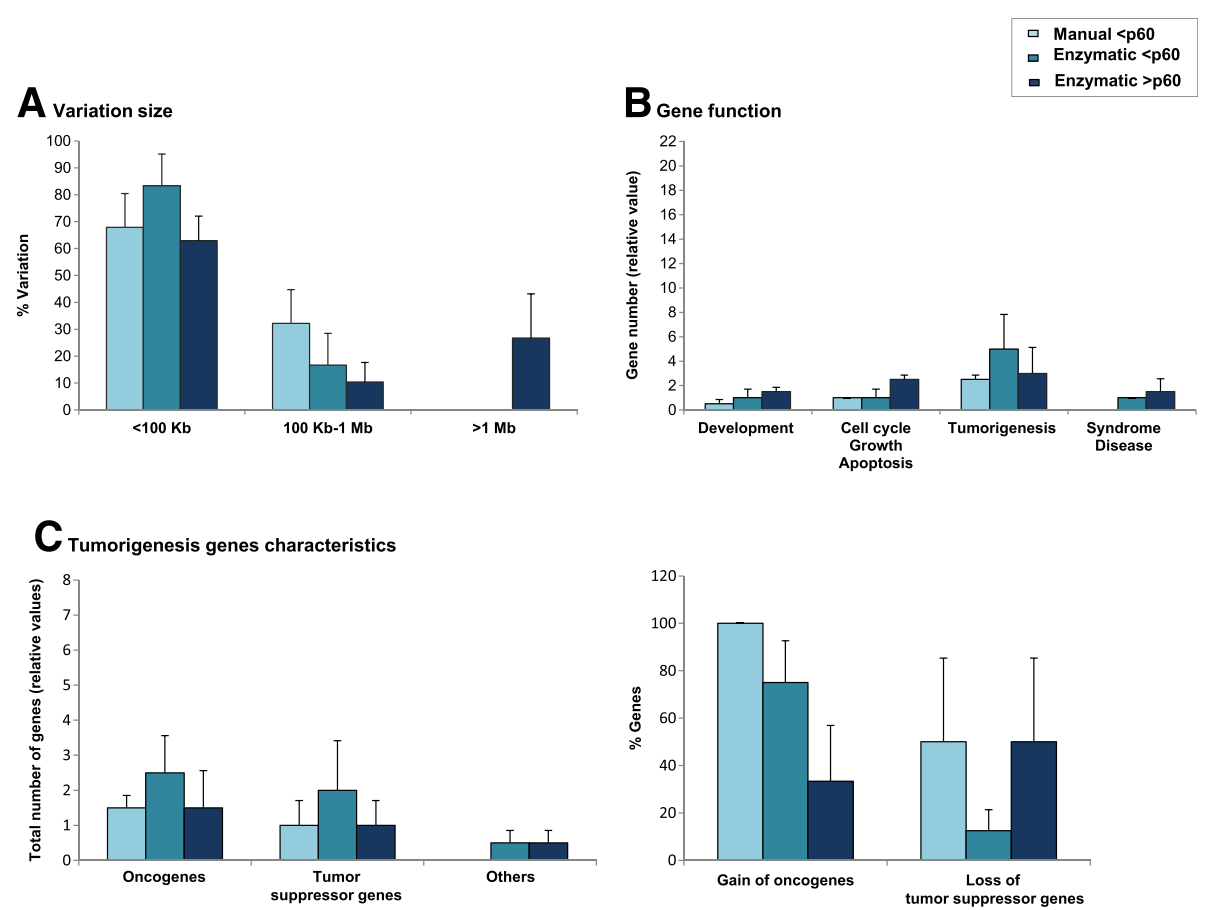

Figure 3 Array-CGH DNA variations without polymorphisms at early manual, early enzymatic and late enzymatic passages. Comparison of genomic variations excluding polymorphic CNVs. Results are presented as mean of the two cell lines (early manual passages, H1 p56, H9p30; early enzymatic passages, H1p56, H9p30; late enzymatic passages, H1p159, H9p87). The criteria evaluated were variation size (A), gene content distributed in 4 groups according to their function: development, cell cycle/growth/apoptosis, tumorigenesis and syndrome/disease (B), and tumorigenesis gene characteristics (C).

intermediate $(16.66 \pm 11.78 \%$ versus $10.34 \pm 7.31 \%)$ and large $(0.00 \pm 0.00 \%$ versus $26.72 \pm 16.46 \%)$ genomic variations (Figure 3A). However, for each group variations $<100 \mathrm{~Kb}$ were more importantly observed. Indeed, for early manual group, small variations were about 2-fold higher than intermediate variations $(67.85 \pm 12.62 \%$ versus $32.14 \pm 12.62 \%)$ and higher than large variations $(67.85 \pm 12.62 \%$ versus $0.00 \pm 0.00 \%, P=$ $0.06)$ (Figure $3 \mathrm{~A}$ ). For early enzymatic group, small variations were about 5 -fold higher than intermediate variations $(83.33 \pm 11.78 \%$ versus $16.66 \pm 11.78 \%)$ and higher than large variations $(83.33 \pm 11.78 \%$ versus $0.00 \pm 0.00 \%)$ (Figure 3A). For late enzymatic group, small variations were about 6-fold higher than intermediate variations $(62.93 \pm 9.14 \%$ versus $10.34 \pm 7.31 \%)$ and by about 4 -fold higher than large variations $(62.93 \pm 9.14 \%$ versus $26.72 \pm$ 16.46\%) (Figure 3A).

For genes carried by genomic variations, we did not observe significant increase of gene number in early enzymatic group versus early manual group independently of what the gene functions are (development, $1.00 \pm 0.70$ versus $0.50 \pm 0.35$; cell cycle/growth/apoptosis, $1.00 \pm$ 0.70 versus $1.00 \pm 0.00$; tumorigenesis, $5.00 \pm 2.82$ versus $2.50 \pm 0.35$; syndrome disease $1.00 \pm 0.00$ versus $0.00 \pm$ $0.00)$; nor in late enzymatic versus early enzymatic groups (development, $1.50 \pm 0.35$ versus $1.00 \pm 0.70$; cell cycle/growth/apoptosis, $2.50 \pm 0.35$ versus $1.00 \pm 0.70$; tumorigenesis, $3.00 \pm 2.12$ versus $5.00 \pm 2.82$; syndrome disease $1.50 \pm 1.06$ versus $1.003 \pm 0.00$ ) (Figure $4 \mathrm{~B}$ ). The list of genes involved in development; cell cycle, growth and apoptosis; tumorigenesis; and syndrome and disease are presented in Additional file 5: Table S1, Additional file 6: Table S2, Additional file 7: Table S3 and Additional file 8 Table S4, respectively.

When looking at tumorigenesis genes, we did not observe differences between early enzymatic versus early manual groups for total number of oncogenes, of tumor suppressor genes or of other genes like fusion genes (oncogenes, $2.50 \pm 1.06$ versus $1.50 \pm 0.35$; tumor suppressor genes, $1.00 \pm 0.70$ versus $2.00 \pm 1.41$; others, $0.50 \pm 0.35$ versus $0.00 \pm 0.00$ ); nor between late enzymatic versus early enzymatic groups (oncogenes, $1.50 \pm 1.06$ versus $2.50 \pm$ 1.06; tumor suppressor genes, $1.00 \pm 0.70$ versus $2.00 \pm$ 1.41 ; others, $0.50 \pm 0.35$ versus $0.50 \pm 0.35$ ) (Figure $4 \mathrm{C}$, left panel). Similarly, the percentage of oncogenes gain and the percentage of tumor suppressor genes loss were not different between early enzymatic versus early manual groups ( $75.00 \pm 17.67 \%$ versus $100.00 \pm 0.00 \%$ and $12.50 \pm 8.83$ versus $50.00 \pm 35.35$, respectively) nor between late versus early enzymatic groups $(33.33 \pm 23.57 \%$ versus $75.00 \pm$ $17.67 \%$ and $50.00 \pm 35.35$ versus $12.50 \pm 8.83$, respectively) (Figure 4C, right panel). 


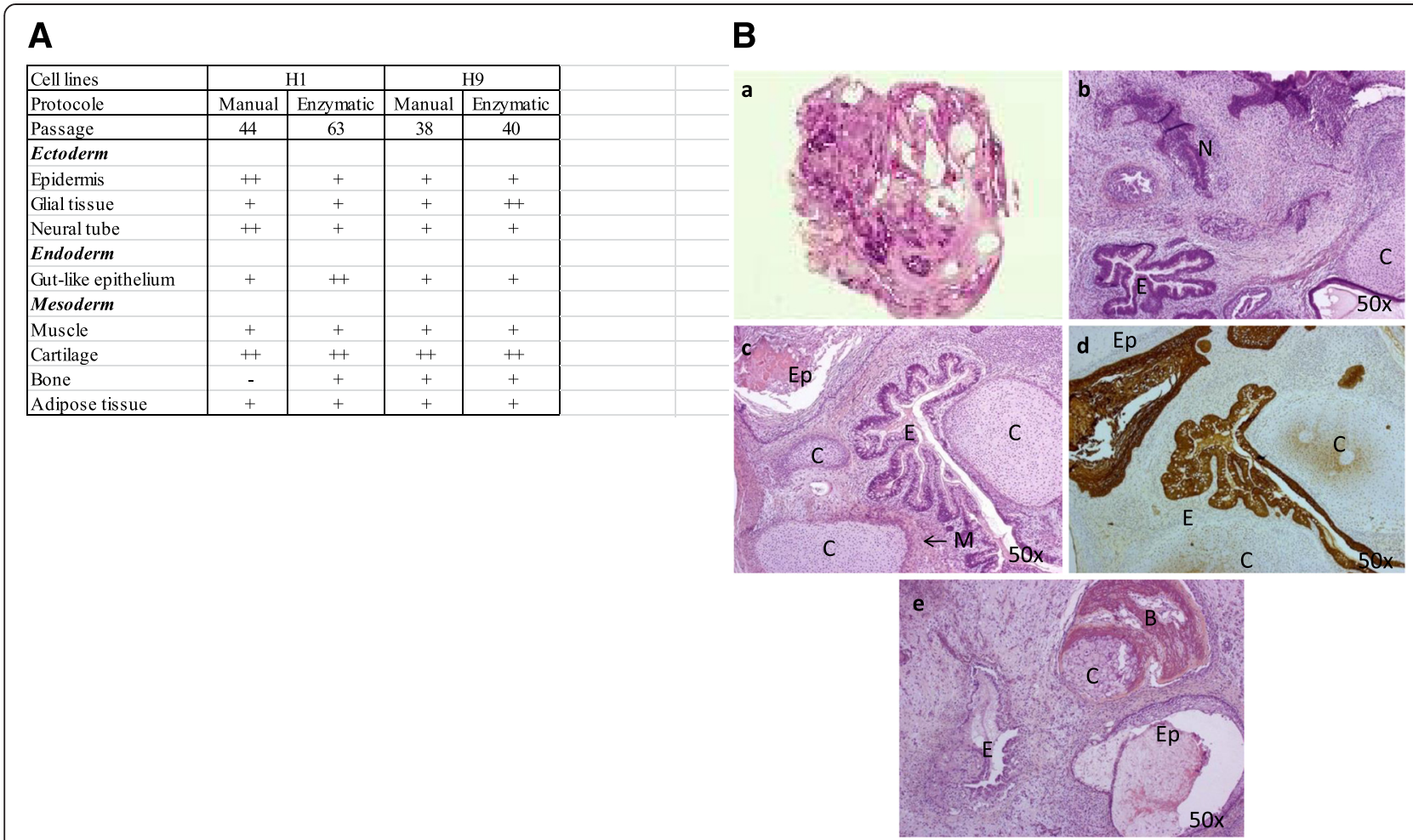

Figure 4 Germ cell layers components within teratomas. Differentiation of H1 and H9 (picked at different passages and dissociated by manual or enzymatic protocols) into ectoderm, endoderm and mesoderm was quantified using whole section Hematoxylin and eosin stains (A). All lines showed structures representing the 3 lineages (ectoderm, endoderm and mesoderm) and were scored as follows: " - indicating the absence of the tissue; " + " and "++ " indicating the existence of differentiated tissues that were respectively moderately (one to 5 focus) or highly ( $>5$ focus) represented. Characteristics of hESC-derived teratomas (B): a, b, c; Hematoxylin and eosin staining of teratoma derived from H1 (passage 63 and treated with enzymatic dissociation). d; Cytokeratin AE1/AE3 immunostaining of teratoma derived from $\mathrm{H} 1$ showing epithelial structures. e; Hematoxylin and eosin staining of teratoma derived from $\mathrm{H} 9$ (passage 40 and treated with enzymatic dissociation). N, neural tissue (ectoderm); C, cartilage (mesoderm); Ep, keratin-containing epidermal tissue (ectoderm); M, striated muscle (mesoderm); B, bone (mesoderm); E, gut epithelial tissue (endoderm).

\section{Evaluation of the differentiation potential of $\mathrm{H} 1$ and $\mathrm{H} 9$ cell lines in vivo}

Teratoma-forming potential and tumor content by histological analysis were explored in the $\mathrm{H} 1$ and $\mathrm{H} 9$ cell lines. This teratoma assay enabled clear-cut evaluation of the impact of both dissociation protocols on the behaviour, the differentiation and the proliferation of hESCs in vivo over a period of several months. Furthermore, the teratoma assay is the only test that may reveal the tumoral potential linked with hESC that have acquired genome alterations and specially genes involved in tumorigenesis or in specific syndrome and disease. For the teratoma assay, 2 to $3 \times 10^{6}$ cells were picked at early (p38/p40/p44) and late (p63) passages were injected intramuscularly. For $\mathrm{H} 1$ and $\mathrm{H} 9$ the two dissociation protocols were compared (Figure 4A). All four hESC produced teratomas after 96 to 160 days. Histological analysis showed a differentiation into ectodermal, endodermal and mesodermal tissues, mainly represented by glial tissues, glandular epitheliums and large cartilaginous areas, respectively (Figure 4B). All the structures observed showed mature and well differentiated tissues without malignancy. Furthermore all teratomas were negative for Ki-1 antigen (CD30) (data not shown) which is highly predictive of pluripotent stem cells-derived malignancies [23], confirming the absence of any embryonic malignant tissues.

In conclusion, for the two hESC lines $\mathrm{H} 1$ and $\mathrm{H} 9$, global genomic variations including polymorphisms were particularly observed in subtelomeric and pericentromeric regions and were mainly of small size $(<100 \mathrm{~Kb})$. The use of collagenase IV did not induced significant differences. When excluding polymorphic genomic variations during data interpretation, we found no effect on gene content neither between early manual versus early enzymatic passages nor between early enzymatic versus late enzymatic passages. Furthermore, both protocols had no functional effect on in vivo malignancy as demonstrated by teratoma assays.

\section{Discussion}

Our results showed that during short and long term culture of the hESC $\mathrm{H} 1$ and $\mathrm{H} 9$, DNA variations were mostly located on instable regions of the genome such 
as subtelomeric and pericentromeric regions. In our study, the use of collagenase IV for cell dissociation did not induce significant changes on genes carried by these genomic variations in comparison with mechanical cell passages.

Genomic variations include single nucleotide polymorphisms (SNP), insertions/duplications, deletions and inversions/translocation. Variability of copy number variation $(\mathrm{CNV})$ is estimated to $10-20 \%$ of the human genome ([24,25], Database of Genomic Variants http:// projects.tcag.ca/cgi-bin/variation/gbrowse/hg18/). The genomic variations are considerated as either polymorphic (or benign, currently referenced in Toronto database of genomic variants), of unknown signification or pathogenic. In our study, we found a mean of twenty-four CNV per hESC line analyzed. The size of CNV ranged from $0.4 \mathrm{~Kb}$ to $3.155 \mathrm{Mb}$, i.e. undetectable using standard karyotype analysis (mean resolution of $10 \mathrm{Mb}$ ). We found more small genomic changes $(<100 \mathrm{~Kb})$ than intermediate $(100 \mathrm{~Kb}-1 \mathrm{Mb})$ and large $(>1 \mathrm{Mb})$ ones. Larger genomic changes have a greater chance of conferring a negative advantage, and of being selected out. We observed that DNA variations were carried by instable regions of the genome such as subtelomeric and pericentromeric regions. Subtelomeric and pericentromeric regions are dynamic chromosomal regions carrying repetitive elements. Other chromosomal regions are considered instable in relation to the architecture of the genome as segmental duplications. These particular conformations of DNA favor deletion and duplication aberrations. Pathogenic CNV may affect gene expression and may influence phenotypic variation by disrupting genes and altering dosage compensation. Thus, DNA copy variations may influence replication/proliferation, differentiation and functional potentials of human ESC.

In the past few years, several authors reported controversial results on genomic integrity during prolonged in vitro hESC culture [2,3,11-16,26-29]. These results may be dependent on the passaging methods used, on the use or not of feeders or on the duration of the culture. Indeed, according to in vitro culture systems, selective pressures from the environment may influence genomic stability. However, genomic stability of hESC lines is essential for maintaining cell properties [30]. Some studies on hESC genomic instability using arrayCGH or SNP array were recently published however the effect of passaging method was not investigated [19-21].

It is important to distinguish random and nonrandom DNA variations. Nonrandom acquired somatic mutations reflect a selective advantage independent of culture conditions. Genomic changes affecting others regions might be more likely to depend upon culture conditions. The International Stem Cell Initiative consortium observed a large differential in frequency between gain and loss of chromosomes, gains being more frequent [20]. Aberrations are located in all chromosomes except chromosome 4 [20]. Some abnormalities such as gain of chromosome 12 (presence of the pluripotency NANOG gene and the cell-cycle regulator CCND2 in 12p13; the oncogene KRAS in 12p12.1), chromosome 17 (BIRC5 candidate gene in $17 q 25$, an antiapoptotic gene associated with the highest-risk tumor), chromosome 20 and chromosome $\mathrm{X}$ or fragments of these chromosomes may promote self-renewal and thus provide a selective proliferative/survival advantage [3,31,32]. Nonrandom abnormalities revealed culture adaptation of human ES as suggested by the ISCI consortium study [20]. ISCI metaanalysis revealed a recurrent loss in 22q13-qter region, as a novel finding. In contrast, other karyotypic abnormalities result in no effect or delayed cell cycle and proliferation rate.

Recurrent genomic variations, as illustrated in Table 1, were observed in the two unrelated hESC lines. This observation suggests that some specific chromosomal regions confer a selective advantage to the cells during in vitro culture. In accordance with published results, we found recurrent gain of 1q21, 20q11.2 and loss of 22q13 regions (Table 1) [4,5,20,31-35]. These three chromosomal regions harbored genes of particular importance for culture adaptation like LCE3C (involved in barrier repair after injury or inflammation, 1q21.3; [36]), BCL2L1 (regulates cell survival and death, 20q11.21; [37]) and SCUBE1 (roles in development, inflammation and thrombosis, 22q13.2; [38]). We found that copy number variation (deletion or duplication) of the 6p21.32 region was systematically detected. The minimal region included the $H L A-D R B 5$ gene, coding for HLA class II beta chain paralogues. The $H L A-D R B 5$ gene is involved in genetic susceptibility to multiple sclerosis (MS) as HLA-DRB5 null subjects appear to be at increased risk for developing secondary progressive MS [39]. Wu and colleagues also described a deletion $6 \mathrm{p} 21.32$ of $40 \mathrm{~Kb}$ including this gene in HSF1 and HSF6 hESC lines using $244 \mathrm{~K}$ array-CGH [33]. The 20q11.21 amplification was described by many authors $[4,5,12,21,33,40]$.

By using array-CGH with a mean resolution of $50 \mathrm{~Kb}$, we failed to detect any significant effect of the passaging method used on hESC genomic instability when comparing manual/mechanical versus enzymatic/collagenase IV methods. However, it cannot be excluded that genomic instability below $50 \mathrm{~Kb}$ could have occurred. This could have been detected by other sensitive methods such as deep genomic sequencing. To our knowledge, published data are still controversial. Caisander and colleague used in their retrospective study karyotype, fluorescent in situ hybridization (FISH) and classic CGH on five hESC lines (SA002, SA002.5, AS034.1.1, SA121 and SA461) after prolonged in vitro culture [16]. When using 
mechanical cell dissociation method, the authors concluded on chromosomal integrity even after two freeze-thaw procedures and 148 passages of cell culture. Catalina study in 2009 used conventional karyotype, spectral karyotyping (SKY), interphase FISH and classic CGH on two hESC lines (HS181, HS293) [17]. The authors concluded on an overall genomic stability whilst maintaining hESC properties (typical morphology, transcription factors and markers expression associated to undifferentiated status and in vitro/in vivo pluripotency). However, mechanical cell dissection combined or not with enzymatic methods may affect cell growth [10,41-44]. During manual passages, colonies are cut into small pieces related to their morphology in contrast to enzymatic methods. However, enzymatic passaging is more efficient in generating sufficient numbers of undifferentiated cells.

An important issue is to evaluate if the genomic alteration and the recurrent genomic variations, which appeared in hESC after repeated passages (with manual or enzymatic techniques) have a strong impact on their differentiation and in tumorigenesis potentials. For this purpose we generated 4 teratomas with hESC picked at early passages. We were able to show that the tested hESCs $\mathrm{H} 1$ and $\mathrm{H} 9$ had the capacity to develop a complete teratoma displaying tissue from all three germ layers. In addition, we did not find any malignant tissue within the teratoma demonstrating that all the observed genomic variations have no impact on the development of malignancy. We also performed a Ki-1 antigen (CD30) immunostaining that was shown previously to be highly predictive of pluripotent stem cells-derived malignancies [23]. All teratomas were negative for CD30 confirming the absence of any embryonic malignant tissues.

\section{Conclusions}

In conclusion, based on our observations we can advocate the utilization of collagenase IV for hESC in vitro culture cell dissociation, a less time-consuming method, compared to the manual passaging method. Indeed, there is no difference on cell genomic integrity at early passages $(<\mathrm{p} 60)$. Furthermore, regardless of the dissociation protocol used, teratoma formation was not associated with embryonic malignant tissues. Our study also showed 9 recurrent copy number variations occurring in hESC culture including the well-known duplication 20q11.21.

\section{Methods}

\section{Human Embryonic Stem Cell (hESC) lines and culture}

All the experiments were approved by the French Biomedical Agency and conducted under the agreement \# RE07-008R. Human embryonic stem cell lines H1 and H9 derived from 46,XY and 46,XX embryos, respectively (Wicell Research Institute, http://www.wicell.org) were maintained into undifferentiated state by continuous culture on a feeder layer of mitomycin $\mathrm{C}$ inactivated mouse embryonic fibroblasts in DMEM/F12 supplemented with 20\% Knock Out Serum Replacer, 1 mM L-glutamine, $0.5 \%$ penicillin/streptomycin, $100 \mu \mathrm{M} 2$-mercaptoethanol and $10 \mathrm{ng} / \mathrm{ml}$ basic FGF (all of them from Invitrogen, Saint-Aubin, France). Cells were weekly passaged by a mechanical method using a 190-210 $\mu \mathrm{m}$ glass pipette (Stem cell cutting tool, Swemed, Bayonne, France) under a stereomicroscope (Lynx, Fisher Bioblock, Strasbourg, France) or by an enzymatic treatment followed by mechanical dissociation ("enzymatic method"). Manual techniques were not performed beyond 60/65 passages. The enzymatic passaging was carried out by incubating the cells in $1 \mathrm{mg} / \mathrm{ml}$ collagenase IV in DMEM/F12 (Invitrogen, Saint-Aubin, France) during $90 \mathrm{~min}$ at $37^{\circ} \mathrm{C}$ and $5 \% \mathrm{CO}_{2}$. Colonies were then collected and pelleted by gravity. After two cycles of washing/sedimentation with DMEM/F12 alone, colonies were mechanically disrupted by 10 times pipetting with a $1 \mathrm{ml}$ micropipette. Additional file 2: Table S5 summarized the passages at which further analysis were realized.

\section{Flow cytometry}

Undifferentiated hESC colonies were recovered from the MEF by incubation in $1 \mathrm{mg} / \mathrm{ml}$ collagenase IV in DMEM/F12 followed by two washes in phosphate buffer saline (Invitrogen, Saint-Aubin, France). Before staining, recovered colonies were incubated in Hank's based enzyme free cell dissociation buffer (Invitrogen, SaintAubin, France) $10 \mathrm{~min}$ at $37^{\circ} \mathrm{C}$ and dissociated to the single cell level by 10 times pipetting with a $1 \mathrm{ml}$ micropipette. Cells were stained using FlowCellect Human ESC (HESCA-1, SSEA-4) Surface Marker Characterization kit (Millipore, Molsheim, France) or PE-conjugated mouse anti-human TRA 1-60 (clone TRA 1-60, BD Biosciences, Le Pont de Claix, France) according to manufacturer's instructions and analyzed on a MACSQuant flow cytometer (Miltenyi Biotec, Paris, France) with MACSQuantify software (Miltenyi Biotec, Paris, France).

\section{Conventional cytogenetic analysis}

Chromosome analyses by standard karyotype were performed from 30 cultured cells using standard procedures (R-bands by heating using Giemsa or RHG, and G-bands by trypsin using Giemsa or GTG bandings) at regular passages. The passage number listed represents the total passage number of the cell line at the time of analysis. For mitotic preparations, cells were cultured in DMEM/ F12 supplemented with $0.02 \mathrm{mg} / \mathrm{ml}$ colchicin (Eurobio, Courtaboeuf, France) for up to $1 \mathrm{~h}$ and $45 \mathrm{~min}$. The cells were harvested and warm hypotonic solution of $0.075 \mathrm{M}$ $\mathrm{KCl}$ was added in the preparation for up to $15-20 \mathrm{~min}$. Finally, the cells were fixed several times in cold Carnoy's fixative (methanol/acetic acid, 3:1). 


\section{Fluorescent in situ hybridization (FISH)}

FISH analyses were performed on 100 interphasic nuclei and 20 metaphase spreads from $\mathrm{H} 1$ and $\mathrm{H} 9$ cell lines at regular passages. The centromeric probes specific for chromosome 12 and 17 were used according to manufacturer's recommendations (Vysis, Downers Grove, IL). BAC clones specific for the 20q11.2 chromosomal region (RP5-1018D12 and RP3-324O17) were used (Bluegnome, Cambridge, UK).

\section{DNA extraction}

Genomic DNA from the two hESC lines was isolated using a DNeasy Blood and Tissu Kit (Qiagen, Courtaboeuf, France). The extracted DNA concentrations were estimated using a NanoDrop ND-1 000 spectrophotometer (NanoDrop Technologies, Wilmington, DE, USA). Extracted DNA was used for array-CGH.

\section{Oligonucleotide array-comparative genomic hybridization (array-CGH)}

The genomic imbalances of the two hESC lines were analyzed by array-CGH using $105 \mathrm{~K}$ oligonucleotide arrays (Hu-105A Agilent Technologies, Massy, France) at early manual passages ( $<60$ passages; H1p56, H9p30), at early enzymatic passages ( $<60$ passages; H1p56, H9p30) and at late enzymatic passages (>60 passages; H1p159, H9p87). The passage number listed represents the total passage number of the cell line at the time of analysis. All array hybridizations were performed according to the manufacturer's recommended protocols. Briefly, $2 \mu \mathrm{g}$ of genomic DNA were digested with AluI (5 units) and RsaI (5 units) for $2 \mathrm{~h}$ at $37^{\circ} \mathrm{C}$ and fluorescently labeled with the Agilent Genomic DNA labeling kit PLUS (Agilent Technologies, Massy, France). Male or female human genomic DNA (Promega, Charbonnière, France) was used as reference. Experiments were done in dye-swap. Cy5-dUTP cell line DNA and gender-matched reference DNA labeled with Cy3-dUTP were denatured and preannealed with Cot-1 DNA and Agilent blocking reagent prior to hybridization for $40 \mathrm{~h}$ at $20 \mathrm{rpm}$ in a $65^{\circ} \mathrm{C}$ rotating hybridization oven (Agilent Technologies, Massy, France). After washing, the slides were scanned on an Agilent Microarray Scanner. Captured images were processed with Feature Extraction 9.1 software and data analysis was performed with DEVA software v1.0.2 (Roche Nimblegen, Meylan, France). The Nexus Copy Number Standard edition software (Proteigene, Saint-Marcel, France) algorithm was used for statistical analysis according to the version 18 of the Human genome built (http://genome.ucsc.edu/). $\mathrm{CNV}$ were considered significant if they were defined by 3 or more oligonucleotides spanned at least $50 \mathrm{~Kb}$. The detection limit for mosaicism rate was arround $10 \%$ as recommended and previously described [45].

\section{Teratoma formation and immunohistochemistry}

The teratoma assay was performed with hESC lines (H1 and H9) by intra-muscular injection of 2 to $3 \times 10^{6}$ of cells into 6-week-old NOD/SCID mice (Charles River Laboratories). H1 cells were injected after 44 and 63 passages performed by mechanical or enzymatic dissociation respectively. $\mathrm{H} 9$ cells were injected after 38 and 40 passages performed by mechanical or enzymatic dissociation respectively. After 96 to 160 days, the teratomas were dissected and fixed in $4 \%$ paraformaldehyde and samples were embedded in paraffin and stained with hematoxylin and eosin in order to assess the presence of ectodermic, endodermic and mesodermic tissues or the presence of malignant tissue. Immunohistochemistry was performed as requested with a Benchmark XT apparatus (Ventana, France) with prediluted primary antibodies raised against AE1/AE3 (anti-pan-cytokeratin, BD Biosciences, France), and Ki-1 antigen CD30 (Ventana).

To evaluate the intensity of CD30-positive areas, an image of the whole teratoma was taken with a digital camera (PCO, Germany) and analyzed by the pathologist. For each histological image, CD30-positive areas and the total surface of the teratoma were manually selected under Adobe Photoshop. The CD30 expression was analyzed in extracts of the different teratomas by using Western blot analysis, as previously described [46]. Briefly, $40 \mu \mathrm{g}$ of protein was loaded in each well, and the nitrocellulose membrane was probed with goat antiCD30 antibody (1:200 Santa cruz-1737). Goat anti-rabbit peroxidase-linked antibody (1:10,000; Promega) was used as a secondary antibody. Actin was detected with monoclonal anti-actin peroxidase conjugated antibody (1:25,000; Sigma-Aldrich).

\section{Statistical analysis}

All array-CGH experimental data are presented as mean \pm SEM. The t-test relative frequencies for independent variables were used to test the differences. Statistical analysis was performed using BiostaTGV online software (http://marne.u707.jussieu.fr/biostatgv/). We compared i. early manual passages versus early enzymatic passages ii. early enzymatic passages versus late enzymatic passages. The differences were assumed to be significant when $\mathrm{P}$-value $<0.05$.

\section{Additional files}

Additional file 1: Figure S1. Pluripotency markers expression. Flow cytometric analysis of HESCA1, SSEA-4 and TRA 1-60 pluripotency markers expression by $\mathrm{H} 1$ at passages 61 (A) and 139 (B), H9 at passages 35 (C) and 69 (D).

Additional file 2: Table S5. Passage number at which analysis were done in hESC lines $\mathrm{H} 1$ and $\mathrm{H} 9$. List of the passage number using either manual or enzymatic (collagenase IV) methods at with flow cytometry, karyotype, array-CGH and teratoma analysis were realized of the hESC lines $\mathrm{H} 1$ and $\mathrm{H}$. 
Additional file 3: Figure S2. Conventional cytogenetic analysis. A. G-banded karyotype of $\mathrm{H} 1 \mathrm{hESC}$ line at passage 64 showing a normal male karyotype 46,XY. B. G-banded karyotype of H9 hESC line at passage 59 showing a normal female karyotype 46,XX.

Additional file 4: Figure S3. Chromosome 1 profile from array-CGH analysis showing recurrent variation on 1q21.3 region. Profiles are illustrated for H1p56 (a; early and manual passage), H1p159 (b; late and enzymatic passage), H9p30 (c; early and manual passage) and H9p87 (d; late and enzymatic passage). For each sample, whole chromosome 1 profile showing the interstitial variation is presented on the left panel; and the 1q21.3 deletion ( $a$ and b) or duplication ( $c$ and $d$ ) is zoomed in the right panel.

Additional file 5: Table S1. Genes related to development. List of genes related to development located in genomic variations corresponding to Figure 3B. Chromosomal position, gene symbol and encoded protein are noted. G, gain; L, loss.

Additional file 6: Table S2. Genes related to cell cycle, growth and apoptosis. List of genes related to cell cycle, growth or apoptosis located in genomic variations corresponding to Figure 3B. Chromosomal position, gene symbol and encoded protein are noted. G, gain; L, loss.

Additional file 7: Table S3. Genes related to tumorigenesis. List of genes related to tumorigenesis located in genomic variations corresponding to Figures $3 \mathrm{~B}$ and $3 \mathrm{C}$. Chromosomal position, gene symbol and encoded protein are noted. G, gain; L, loss.

Additional file 8: Table S4. Genes related to syndrome and disease. List of genes related to syndrome or human disease located in genomic variations corresponding to Figure 3B. Chromosomal position, gene symbol and encoded protein are noted. G, gain; L, loss.

\section{Abbreviations}

array-CGH: microarray-based comparative genomic hybridization; CNV: Copy number variation; FISH: Fluorescent in situ hybridization; GTG: G-bands by trypsin using Giemsa; hESC: Human embryonic stem cells; MEF: Mouse embryonic fibroblasts; RHG: R-bands by heating using Giemsa; SKY: Spectral karyotyping; SNP: Single nucleotide polymorphisms.

\section{Competing interests}

The authors declare that they have no competing interests.

\section{Authors' contributions}

LT conceived the study and drafted the manuscript. ABG provided cell lines. OF and AM cultured cell lines. FG performed teraroma assay. LT and CB collected and assembled the data. LT and GT carried out data analysis and interpretation. GT provided genetic tools, conceived the study and helped to draft the manuscript. Revised the manuscript critically for important intellectual content. All authors read and approved the final manuscript.

\section{Acknowledgments}

This study has been supported in part by additional grants from Medicen Paris Region (IngeCELL).

\section{Author details}

${ }^{1}$ AP-HP, Histologie-Embryologie-Cytogénétique, Hôpitaux Universitaires Paris Sud, Clamart F-92141, France. ${ }^{2}$ Université Paris Sud, Le Kremlin-Bicêtre F-94275, France. ${ }^{3}$ Esteam Paris Sud INSERM UMR-S 935, Villejuif F-94801, France. ${ }^{4}$ Université Paris Descartes, Sorbonne Paris Cité F-75006, France. ${ }^{5}$ AP-HP, Hématologie, Hôpitaux Universitaires Paris Sud, Villejuif F-94801, France.

Received: 7 January 2015 Accepted: 7 April 2015

Published online: 23 April 2015

\section{References}

1. Thomson JA, Itskovitz-Eldor J, Shapiro SS, Waknitz MA, Swiergiel JJ, Marshall VS, et al. Embryonic stem cell lines derived from human blastocysts. Science. 1998:282:1145-7.

2. Draper JS, Smith K, Gokhale P, Moore HD, Maltby E, Johnson J, et al. Recurrent gain of chromosomes $17 \mathrm{q}$ and 12 in cultured human embryonic stem cells. Nat Biotechnol. 2004;22:53-4.
3. Baker DE, Harrison NJ, Maltby E, Smith K, Moore HD, Shaw PJ, et al. Adaptation to culture of human embryonic stem cells and oncogenesis in vivo. Nat Biotechnol. 2007;25:207-15.

4. Lefort N, Feyeux M, Bas C, Féraud O, Bennaceur-Griscelli A, Tachdjian G, et al. Human embryonic stem cells reveal recurrent genomic instability at 20q11.21. Nat Biotechnol. 2008;26:1364-6.

5. Krutá M, Bálek L, Hejnová R, Dobšáková Z, Eiselleová L, Matulka K, et al. Decrease in abundance of apurinic/apyrimidinic endonuclease causes failure of base excision repair in culture-adapted human embryonic stem cells. Stem Cells. 2013;31:693-702.

6. Holubcová Z, Matula P, Sedláčková M, Vinarský V, Doležalová D, Bárta T, et al. Human embryonic stem cells suffer from centrosomal amplification. Stem Cells. 2011;29:46-56.

7. Bárta T, Vinarský V, Holubcová Z, Dolezalová D, Verner J, Pospísilová S, et al. Human embryonic stem cells are capable of executing G1/S checkpoint activation. Stem Cells. 2010;28:1143-52.

8. Spits C, Mateizel I, Geens M, Mertzanidou A, Staessen C, Vandeskelde Y, et al. Recurrent chromosomal abnormalities in human embryonic stem cells. Nat Biotechnol. 2008;26:1361-3.

9. Amit M, Carpenter MK, Inokuma MS, Chiu CP, Harris CP, Waknitz MA, et al. Clonally derived human embryonic stem cell lines maintain pluripotency and proliferative potential for prolonged periods of culture. Dev Biol. 2000;227:271-8.

10. Cowan CA, Klimanskaya I, McMahon J, Atienza J, Witmyer J, Zucker JP, et al. Derivation of embryonic stem-cell lines from human blastocysts. N Engl J Med. 2004;350:1353-6.

11. Inzunza J, Sahlén S, Holmberg K, Strömberg AM, Teerijoki H, Blennow E, et al. Comparative genomic hybridization and karyotyping of human embryonic stem cells reveals the occurrence of an isodicentric $X$ chromosome after long-term cultivation. Mol Hum Reprod. 2004;10:461-6.

12. Maitra A, Arking DE, Shivapurkar N, Ikeda M, Stastny V, Kassauei K, et al. Genomic alterations in cultured human embryonic stem cells. Nat Genet. 2005;37:1099-103.

13. Mitalipova MM, Rao RR, Hoyer DM, Johnson JA, Meisner LF, Jones KL, et al. Preserving the genetic integrity of human embryonic stem cells. Nat Biotechnol. 2005:23:19-20.

14. Chan EM, Yates F, Boyer LF, Schlaeger TM, Daley GQ. Enhanced plating efficiency of trypsin-adapted human embryonic stem cells is reversible and independent of trisomy 12/17. Cloning Stem Cells. 2008;10:107-18.

15. Yang $S$, Lin G, Tan YQ, Deng LY, Yuan D, Lu GX. Differences between karyotypically normal and abnormal human embryonic stem cells. Cell Prolif. 2010:43:195-206

16. Caisander G, Park H, Frej K, Lindqvist J, Bergh C, Lundin K, et al. Chromosomal integrity maintained in five human embryonic stem cell lines after prolonged in vitro culture. Chromosome Res. 2006;14:131-7.

17. Catalina P, Bueno C, Montes R, Nieto A, Ligero G, Sanchez L, et al. Genetic stability of human embryonic stem cells: a first-step toward the development of potential hESC-based systems for modeling childhood. Leuk Res. 2009;33:980-90.

18. T'joen V, Declercq H, Cornelissen M. Expansion of human embryonic stem cells: a comparative study. Cell Prolif. 2011;44:462-76.

19. Närvä E, Autio R, Rahkonen N, Kong L, Harrison N, Kitsberg D, et al. Highresolution DNA analysis of human embryonic stem cell lines reveals cultureinduced copy number changes and loss of heterozygosity. Nat Biotechnol. 2010;28:371-7.

20. International Stem Cell Initiative, Amps K, Andrews PW, Anyfantis G, Armstrong L, Avery $S$, et al. Screening ethnically diverse human embryonic stem cells identifies a chromosome 20 minimal amplicon conferring growth advantage. Nat Biotechnol. 2011;29:1132-44.

21. Laurent LC, Ulitsky I, Slavin I, Tran H, Schork A, Morey R, et al. Dynamic changes in the copy number of pluripotency and cell proliferation genes in human ESCS and iPSCs during reprogramming and time in culture. Cell Stem Cell. 2011:8:106-18.

22. Bai Q, Ramirez JM, Becker F, Pantesco V, Lavabre-Bertrand T, Hovatta O, et al. Temporal analysis of genome alterations induced by single-cell passaging in human embryonic stem cells. Stem Cells Dev. 2014;24(5):653-62.

23. Griscelli F, Féraud O, Oudrhiri N, Gobbo E, Casal I, Chomel JC, et al. Malignant germ cell-like tumors, expressing Ki-1 antigen (CD30), are revealed during in vivo differentiation of partially reprogrammed human-induced pluripotent stem cells. Am J Pathol. 2012;180:2084-96. 
24. Carter NP. Methods and strategies for analyzing copy number variation using DNA microarrays. Nat Genet. 2007;39:S16-21.

25. Pinto D, Marshall C, Feuk L, Scherer SW. Copy-number variation in control population cohorts. Hum Mol Genet. 2007;16:R168-73.

26. Buzzard JJ, Gough NM, Crook JM, Colman A. Karyotype of human ES cells during extended culture. Nat Biotechnol. 2004;22:381-2

27. Pera MF. Unnatural selection of cultured human ES cells? Nat Biotechnol. 2004;22:42-3.

28. Imreh MP, Gertow K, Cedervall J, Unger C, Holmberg K, Szöke K, et al. In vitro culture conditions favoring selection of chromosomal abnormalities in human ES cells. J Cell Biochem. 2006:99:508-16.

29. Gertow K, Cedervall J, Unger C, Szöke K, Blennow E, Imreh MP, et al. Trisomy 12 in HESC leads to no selective in vivo growth advantage in teratomas, but induces an increased abundance of renal development. J Cell Biochem. 2007;100:1518-25.

30. Moon SH, Kim JS, Park SJ, Lim JJ, Lee HJ, Lee SM, et al. Effect of chromosome instability on the maintenance and differentiation of human embryonic stem cells in vitro and in vivo. Stem Cell Res. 2011;6:50-9.

31. Nguyen HT, Geens M, Mertzanidou A, Jacobs K, Heirman C, Breckpot K, et al. Gain of 20q11.21 in human embryonic stem cells improves cell survival by increased expression of BCl-xL. Mol Hum Reprod. 2013;20:168-77.

32. Avery S, Hirst AJ, Baker D, Lim CY, Alagaratnam S, Skotheim Rl, et al. BCL-XL mediates the strong selective advantage of a 20q11.21 amplification commonly found in human embryonic stem cell cultures. Stem Cell Reports. 2013;1:379-86.

33. Wu H, Kim K, Mehta K, Paxia S, Sundstrom A, Anantharaman T, et al. Copy number variant analysis of human embryonic stem cells. Stem Cells. 2008:26:1484-9.

34. Lund RJ, Närvä E, Lahesmaa R. Genetic and epigenetic stability of human pluripotent stem cells. Nat Rev Genet. 2012;13:732-44.

35. Nguyen $H T$, Geens $M$, Spits $C$. Genetic and epigenetic instability in human pluripotent stem cells. Hum Reprod Update. 2013;19:187-205.

36. Bergboer JG, Tjabringa GS, Kamsteeg M, van Vlijmen-Willems IM, RodijkOlthuis $D$, Jansen PA, et al. Psoriasis risk genes of the late cornified envelope-3 group are distinctly expressed compared with genes of other LCE groups. Am J Pathol. 2011;178:1470-7.

37. Bai H, Chen K, Gao YX, Arzigian M, Xie YL, Malcosky C, et al. Bcl-xL enhances single-cell survival and expansion of human embryonic stem cells without affecting self-renewal. Stem Cell Res. 2012;8:26-37.

38. Yang RB, Ng CK, Wasserman SM, Colman SD, Shenoy S, Mehraban F, et al. Identification of a novel family of cell-surface proteins expressed in human vascular endothelium. J Biol Chem. 2002;277:46364-73.

39. Caillier SJ, Briggs F, Cree BA, Baranzini SE, Fernandez-Viña M, Ramsay PP, et al. Uncoupling the roles of HLA-DRB1 and HLA-DRB5 genes in multiple sclerosis. J Immunol. 2008;181:5473-80.

40. Werbowetski-Ogilvie TE, Bossé M, Stewart M, Schnerch A, Ramos-Mejia V, Rouleau A, et al. Characterization of human embryonic stem cells with features of neoplastic progression. Nat Biotechnol. 2009;27:91-7.

41. Xu C, Inokuma MS, Denham J, Golds K, Kundu P, Gold JD, et al. Feeder-free growth of undifferentiated human embryonic stem cells. Nat Biotechnol. 2001:19:971-4

42. Heins N, Englund MC, Sjöblom C, Dahl U, Tonning A, Bergh C, et al. Derivation, characterization, and differentiation of human embryonic stem cells. Stem Cells. 2004;22:367-76.

43. Koivisto H, Hyvärinen M, Strömberg AM, Inzunza J, Matilainen E, Mikkola M, et al. Cultures of human embryonic stem cells: serum replacement medium or serum-containing media and the effect of basic fibroblast growth factor. Reprod Biomed Online. 2004;9:330-7.

44. Stojkovic P, Lako M, Stewart R, Przyborski S, Armstrong L, Evans J, et al. An autogeneic feeder cell system that efficiently supports growth of undifferentiated human embryonic stem cells. Stem Cells. 2005;23:306-14.

45. Neill NJ, Torchia BS, Bejjani BA, Shaffer LG, Ballif BC. Comparative analysis of copy number detection by whole-genome BAC and oligonucleotide array CGH. Mol Cytogenet. 2010;3(11):1755-8166.

46. Galaup A, Magnon C, Rouffiac V, Opolon P, Opolon D, Lassau N, et al. Full kringles of plasminogen (aa 1-566) mediate complete regression of human MDA-MB-231 breast tumor xenografted in nude mice. Gene Ther. 2005:12:831-42

\section{Submit your next manuscript to BioMed Central and take full advantage of:}

- Convenient online submission

- Thorough peer review

- No space constraints or color figure charges

- Immediate publication on acceptance

- Inclusion in PubMed, CAS, Scopus and Google Scholar

- Research which is freely available for redistribution

Submit your manuscript at www.biomedcentral.com/submit 